\title{
Renin-angiotensin system inhibitors and the severity of coronavirus disease 2019 in Kanagawa, Japan: a retrospective cohort study
}

\author{
Yasushi Matsuzawa ${ }^{1} \cdot$ Hisao Ogawa $^{2} \cdot K^{K a z u o ~ K i m u r a}{ }^{1} \cdot$ Masaaki Konishi ${ }^{3} \cdot$ Jin Kirigaya $^{4} \cdot$ Kazuki Fukui $^{5} \cdot$ \\ Kengo Tsukahara ${ }^{6} \cdot$ Hiroyuki Shimizu $^{7} \cdot$ Keisuke Iwabuchi $^{8} \cdot$ Yu Yamada $^{9} \cdot$ Kenichiro Saka $^{10} \cdot$ Ichiro Takeuchi $^{4}$. \\ Toshio Hirano ${ }^{11} \cdot$ Kouichi Tamura ${ }^{3}$
}

Received: 2 July 2020 / Revised: 15 July 2020 / Accepted: 15 July 2020 / Published online: 21 August 2020

(C) The Japanese Society of Hypertension 2020

\begin{abstract}
Since the beginning of the coronavirus disease 2019 (COVID-19) outbreak initiated on the Diamond Princess Cruise Ship at Yokohama harbor in February 2020, we have been doing our best to treat COVID-19 patients. In animal experiments, angiotensin converting enzyme inhibitors (ACEIs) and angiotensin II type-1 receptor blockers (ARBs) are reported to suppress the downregulation of angiotensin converting enzyme 2 (ACE2), and they may inhibit the worsening of pathological conditions. We aimed to examine whether preceding use of ACEIs and ARBs affected the clinical manifestations and prognosis of COVID-19 patients. One hundred fifty-one consecutive patients (mean age $60 \pm 19$ years) with polymerase-chain-reaction proven severe acute respiratory syndrome coronavirus 2 (SARS-CoV-2) infection who were admitted to six hospitals in Kanagawa Prefecture, Japan, were analyzed in this multicenter retrospective observational study. Among all COVID-19 patients, in the multiple regression analysis, older age (age $\geq 65$ years) was significantly associated with the primary composite outcome (odds ratio (OR) 6.63, 95\% confidence interval (CI) $2.28-22.78, P<0.001$ ), which consisted of (i) in-hospital death, (ii) extracorporeal membrane oxygenation, (iii) mechanical ventilation, including invasive and noninvasive methods, and (iv) admission to the intensive care unit. In COVID-19 patients with hypertension, preceding ACEI/ARB use was significantly associated with a lower occurrence of new-onset or worsening mental confusion (OR 0.06, 95\% CI 0.002-0.69, $P=0.02$ ), which was defined by the confusion criterion, which included mild disorientation or hallucination with an estimation of medical history of mental status, after adjustment for age, sex, and diabetes. In conclusion, older age was a significant contributor to a worse prognosis in COVID-19 patients, and ACEIs/ARBs could be beneficial for the prevention of confusion in COVID-19 patients with hypertension.
\end{abstract}

Keywords Angiotensin converting enzyme inhibitors · Angiotensin II type-1 receptor blockers · COVID-19

Yasushi Matsuzawa

matsu@yokohama-cu.ac.jp

1 Division of Cardiology, Yokohama City University Medical Center, Yokohama, Japan

2 National Cerebral and Cardiovascular Center, Suita, Japan

3 Department of Medical Science and Cardiorenal Medicine, Yokohama City University Graduate School of Medicine, Yokohama, Japan

4 Department of Emergency Medicine, Yokohama City University Graduate School of Medicine, Yokohama, Japan

5 Department of Cardiology, Kanagawa Cardiovascular and Respiratory Center, Yokohama, Japan
6 Division of Cardiology, Fujisawa City Hospital, Fujisawa, Japan

7 Department of Clinical Laboratory Medicine, Fujisawa City Hospital, Fujisawa, Japan

8 Department of General Medicine, Kanagawa Prefectural Ashigarakami Hospital, Ashigara, Japan

9 Division of Cardiology, Kanagawa Prefectural Ashigarakami Hospital, Ashigara, Japan

10 Division of Cardiology, Yokosuka City Hospital, Yokosuka, Japan

11 Headquarters, National Institutes for Quantum and Radiological Science and Technology, Chiba, Japan 


\section{Introduction}

The novel severe acute respiratory syndrome coronavirus-2 (SARS-CoV-2), which causes coronavirus disease 2019 (COVID-19), emerged in Wuhan, Hubei Province, China, and has been rapidly spreading worldwide. In Japan, the outbreak of COVID-19 initiated on the Diamond Princess Cruise Ship at Yokohama harbor, leading to a nationwide pandemic. Since the beginning of the COVID-19 outbreak, we have been treating COVID-19 patients to the best of our ability. In addition, the Japanese Society of Hypertension assembled a task force for the COVID-19 pandemic, and its members have been energetically working on issues regarding hypertension and COVID-19, using YouTube for primary care doctors, suggesting a "new normal" for hypertension medicine [1,2].

SARS-CoV-2 enters human cells by utilizing angiotensin converting enzyme 2 (ACE2) as a receptor, and infection can progress to acute respiratory distress syndrome (ARDS). ARDS is the most severe form of acute lung injury, with alveolar inflammation, pneumonia, and hypoxic lung conditions, resulting in respiratory failure, multiple organ failure, and death in 50\% of ARDS patients [3]. It has been suggested that the progression and protraction of ARDS is related to hyperimmune responses to SARS and cytokine storms $[4,5]$.

Although several studies have reported that renin-angiotensin system (RAS) inhibitors such as ACE inhibitors (ACEIs) and angiotensin II type-1 receptor blockers (ARBs) may increase the expression of ACE2 $[6,7]$, recent large cohort studies have reported that there is no association between the use of RAS inhibitors and susceptibility to SARS-CoV-2 infection [8-10]. More importantly, ACE2 can catabolize angiotensin II as a counterregulatory enzyme to the activity of the RAS and is protective against detrimental hyperactivation of the RAS, inflammatory cytokine release, and subsequent ARDSmediated death [11]. Therefore, RAS inhibitors may improve the clinical manifestations and prognosis of COVID-19 by blocking the downregulation of ACE2, hyperactivation of the RAS, and cytokine storm; however, this is still controversial [1].

We hypothesized that pretreatment with ACEIs or ARBs reduces the extent of lung injury by SARS-CoV-2 and improves clinical outcomes through the inhibition of the RAS.

\section{Methods}

\section{Study design and patient population}

The present study, Kanagawa RASI COVID-19 study, is a multicenter retrospective observational study of patients diagnosed with COVID-19 by polymerase chain reaction (PCR). Six hospitals in Kanagawa Prefecture, Japan, including (1) Yokohama City University Medical Center, (2) Kanagawa Cardiovascular and Respiratory Center, (3) Fujisawa City Hospital, 4) Kanagawa Prefectural Ashigarakami Hospital, (5) Yokosuka City Hospital, and (6) Yokohama City University Hospital, contributed patient data for analysis. Patients were admitted between February 1st and May 1st, 2020. The final date of follow-up was May 20th, 2020. All data were retrospectively collected from medical records. The definitions of hypertension and other past medical histories were based on history taking by attending doctors, medications on admission, and medical information from other hospitals.

This study was approved by the institutional review boards. Our observational study was designed by the authors and approved with a waiver of authorization and informed consent by the Institutional Review Board of Yokohama City University.

\section{Definition of outcomes}

The primary composite outcome was defined as follows: (i) in-hospital death, (ii) extracorporeal membrane oxygenation, (iii) mechanical ventilation, including invasive and noninvasive methods, and (iv) admission to the intensive care unit (ICU). The secondary composite outcome included (i) oxygen therapy for low percutaneous oxygen saturation $\leq 90 \%$, (ii) new-onset or worsening mental confusion, (iii) systolic blood pressure $\leq 90 \mathrm{mmHg}$ on admission, and (iv) evidence of pneumonia by computed tomography (CT) scan. New-onset or worsening mental confusion was defined by the confusion criterion, which included mild disorientation or hallucination with an estimation of medical history of mental status. "Severe pneumonia" was defined as a composite of in-hospital death related to pneumonia, extracorporeal membrane oxygenation, mechanical ventilation, and oxygen therapy. The primary and secondary composite outcomes and the "severe pneumonia" composite outcome were assessed for the entire study population and compared between patients with hypertension and those without hypertension. Furthermore, in patients with hypertension, these outcomes were compared between patients with ACEI/ARB use and those without ACEI/ARB use.

\section{Statistical analysis}

The patients were divided into two groups according to hypertension (the hypertension group and the nonhypertension group), and patients with hypertension were 
Table 1 Patient characteristics according to hypertension in overall COVID-19 patients

\begin{tabular}{|c|c|c|c|c|}
\hline & $\begin{array}{l}\text { Total } \\
n=151\end{array}$ & $\begin{array}{l}\text { Non-hypertension } \\
n=112\end{array}$ & $\begin{array}{l}\text { Hypertension } \\
n=39\end{array}$ & $P$ value \\
\hline Age, year & $60 \pm 19$ & $56 \pm 20$ & $71 \pm 12$ & $<0.001$ \\
\hline Male sex, $\%$ & 59.6 & 56.3 & 69.2 & 0.15 \\
\hline Height, cm & $165 \pm 10$ & $166 \pm 10$ & $163 \pm 12$ & 0.25 \\
\hline Body weight, $\mathrm{kg}$ & $66 \pm 13$ & $65 \pm 12$ & $68 \pm 17$ & 0.24 \\
\hline Systolic blood pressure, $\mathrm{mmHg}$ & $134 \pm 24$ & $131 \pm 22$ & $143 \pm 26$ & 0.008 \\
\hline Diastolic blood pressure, $\mathrm{mmHg}$ & $81 \pm 15$ & $81 \pm 14$ & $83 \pm 20$ & 0.39 \\
\hline Heart rate, /min & $87 \pm 16$ & $87 \pm 16$ & $86 \pm 16$ & 0.82 \\
\hline Body temperature $\geq 37^{\circ} \mathrm{C}, \%$ & 50.3 & 44.6 & 66.7 & 0.018 \\
\hline Smoking & & & & 0.62 \\
\hline Current, \% & 7.2 & 7.4 & 6.7 & \\
\hline Former, \% & 33.6 & 35.8 & 26.7 & \\
\hline Never, \% & 59.2 & 56.8 & 66.7 & \\
\hline Diabetes mellitus, $\%$ & 20.5 & 15.2 & 35.9 & 0.006 \\
\hline Myocardial infarction, \% & 0 & 0 & 0 & $>0.99$ \\
\hline Heart failure, $\%$ & 2.0 & 1.8 & 2.6 & 0.76 \\
\hline Stroke, $\%$ & 2.0 & 0 & 7.7 & 0.003 \\
\hline Chronic obstructive pulmonary disease, $\%$ & 3.3 & 3.6 & 2.6 & 0.76 \\
\hline Chronic kidney disease, $\%$ & 3.3 & 1.8 & 7.7 & 0.076 \\
\hline Immunosuppressed condition, $\%$ & 0.66 & 0.89 & 0 & 0.55 \\
\hline \multicolumn{5}{|l|}{ Medications on admission } \\
\hline ACE-I, \% & 2.0 & 0 & 7.7 & 0.003 \\
\hline $\mathrm{ARB}, \%$ & 12.6 & 0.9 & 46.2 & $<0.001$ \\
\hline Direct renin inhibitor, $\%$ & 0 & 0 & 0 & $>0.99$ \\
\hline Calcium channel blocker, $\%$ & 14.8 & 0 & 56.4 & $<0.001$ \\
\hline$\beta$-blocker, $\%$ & 1.3 & 0 & 5.1 & 0.016 \\
\hline Antidiabetic drugs, $\%$ & 13.3 & 9.0 & 25.6 & 0.009 \\
\hline Statin, \% & 15.4 & 11.7 & 25.6 & 0.038 \\
\hline \multicolumn{5}{|l|}{ Laboratory data on admission } \\
\hline Leukocytes, $10^{9} / 1$ & $5.3(4.3-7.0)$ & $5.3(4.3-7.1)$ & $5.3(4.4-6.7)$ & 0.99 \\
\hline Neutrophils, $10^{9} / 1$ & $3.6(2.6-5.0)$ & $3.6(2.5-5.0)$ & $3.7(3.0-4.7)$ & 0.54 \\
\hline Platelets, $10^{9} / 1$ & $200(164-267)$ & $211(166-267)$ & $177(160-266)$ & 0.26 \\
\hline Hemoglobin, g/dl & $14.3(12.8-15.4)$ & $14.6(13.1-15.5)$ & $14.1(11.5-15.0)$ & 0.044 \\
\hline AST, IU/l & $36 \pm 22$ & $34 \pm 20$ & $43 \pm 26$ & 0.026 \\
\hline ALT, IU/l & $35 \pm 34$ & $34 \pm 35$ & $39 \pm 32$ & 0.45 \\
\hline$\gamma$-GTP, IU/l & $58 \pm 65$ & $58 \pm 71$ & $58 \pm 42$ & 0.97 \\
\hline Total bilirubin, mg/dl & $0.6 \pm 0.4$ & $0.6 \pm 0.4$ & $0.7 \pm 0.5$ & 0.53 \\
\hline Total protein, g/dl & $7.1 \pm 0.7$ & $7.2 \pm 0.7$ & $6.8 \pm 0.5$ & 0.002 \\
\hline Albumin, g/dl & $3.7 \pm 0.7$ & $3.8 \pm 0.7$ & $3.3 \pm 0.5$ & 0.003 \\
\hline Glucose, mg/dl & $113(100-139)$ & $110(99-130)$ & $122(108-173)$ & 0.01 \\
\hline Total cholesterol, mg/dl & $172 \pm 41$ & $183 \pm 45$ & $151 \pm 24$ & 0.022 \\
\hline LDL-cholesterol, mg/dl & $95 \pm 35$ & $101 \pm 39$ & $81 \pm 22$ & 0.14 \\
\hline HDL-cholesterol, mg/dl & $49 \pm 16$ & $48 \pm 15$ & $53 \pm 20$ & 0.46 \\
\hline Trigrycerides, mg/dl & $119(85-161)$ & $124(85-166)$ & $101(82-138)$ & 0.46 \\
\hline Creatinine, $\mathrm{mg} / \mathrm{dl}$ & $0.9 \pm 0.4$ & $0.8 \pm 0.2$ & $1.1 \pm 0.7$ & $<0.001$ \\
\hline BUN, mg/dl & $16 \pm 9$ & $15 \pm 7$ & $19 \pm 14$ & 0.021 \\
\hline $\mathrm{Na}, \mathrm{mEq} / \mathrm{l}$ & $138 \pm 4$ & $138 \pm 4$ & $137 \pm 4$ & 0.14 \\
\hline Urine protein (102 patients) & & & & 0.14 \\
\hline,$- \%$ & 29.7 & 34.6 & 13.0 & \\
\hline, $\pm \%$ & 21.8 & 20.5 & 26.1 & \\
\hline,$+ \%$ & 48.5 & 44.9 & 60.9 & \\
\hline $\mathrm{C}$-reactive protein, $\mathrm{mg} / \mathrm{dl}$ & $1.7(0.5-7.5)$ & $1.3(0.3-7.0)$ & $5.4(1.4-8.5)$ & 0.007 \\
\hline
\end{tabular}

Data are shown as mean \pm standard deviation, median (interquartile range), or percentage

$A C E-I$ angiotensin converting enzyme inhibitor, $A L T$ alanine aminotransferase, $A S T$ aspartate transaminase, $A R B$ angiotensin II receptor blocker, $B U N$ blood urea nitrogen, COVID-19 coronavirus disease-2019, $H D L$ high density lipoprotein, $L D L$ low density lipoprotein 
further divided based on ACEI/ARB use (the ACEI/ARB group and the non-ACEI/ARB group). Continuous variables are shown as either means \pm standard deviations (SDs) or medians (interquartile ranges). Categorical variables are presented as numbers $(\%)$. Continuous variables were compared with the Student's $t$ test or Mann-Whitney U-test, and categorical variables were compared with the Fisher's exact test. Univariate and multivariate logistic regression analysis was used to evaluate factors associated with the primary and secondary outcomes and the "severe pneumonia" composite outcome. Statistical significance was defined as a twosided value of $P<0.05$. All data analyses were performed using JMP Version 12.1.0 (12.0).

\section{Results}

\section{Patient characteristics}

A total of 151 continuous patients hospitalized with COVID-19 were enrolled in this study. The mean \pm SD of age was $60 \pm 19$ years, and $59.6 \%$ of the patients were male. The clinical characteristics of our cohort are shown in Table 1. Among the 151 patients, 39 (25.8\%) patients had hypertension, $31(20.5 \%)$ had diabetes, and ACEI/ARBs were prescribed in $22(14.6 \%)$ patients (ACEIs: 3 (2.0\%); ARBs: 19 (12.6\%)). COVID-19 patients with hypertension were significantly older and had higher systolic blood pressure, body temperature, aspartate aminotransferase, blood glucose, creatinine, blood urea nitrogen, and Creactive protein and lower total protein, albumin, and total cholesterol on admission than those without hypertension. Diabetes mellitus and a history of stroke were more prevalent in COVID-19 patients with hypertension than in those without hypertension.

Table 2 shows the clinical characteristics of COVID-19 patients with hypertension according to ACEI/ARB use. The mean age was comparable between the patients with ACEI/ARB use and those without ACEI/ARB use. The patients taking ACEIs/ARBs had a greater prevalence of diabetes mellitus $(52.4 \%$ versus $16.7 \%, P=0.021)$ and lower low-density lipoprotein cholesterol.

\section{Outcomes in the entire study population}

In this study, there were 14 (9.3\%) in-hospital deaths, and mechanical ventilation or oxygen therapy was required in $14(9.3 \%)$ and $58(38.4 \%)$ patients, respectively. Mental confusion related to pneumonia and systolic blood pressure $<90 \mathrm{mmHg}$ on admission were observed in $14(9.3 \%)$ and $3(2.0 \%)$ patients, respectively. SARS-CoV-2 infection was the cause of confusion in 13 patients. The other
Table 2 Patient characteristics according to ACEI/ARB use in COVID-19 patients with hypertension

\begin{tabular}{|c|c|c|c|}
\hline & $\begin{array}{l}\text { Non-ACEI/ARB } \\
n=18\end{array}$ & $\begin{array}{l}\text { ACEI/ARB } \\
n=21\end{array}$ & $P$ value \\
\hline Age, year & $72 \pm 12$ & $71 \pm 11$ & 0.86 \\
\hline Male sex, $\%$ & 77.8 & 61.9 & 0.28 \\
\hline Height, cm & $166 \pm 12$ & $161 \pm 11$ & 0.25 \\
\hline Body weight, $\mathrm{kg}$ & $66 \pm 16$ & $69 \pm 18$ & 0.65 \\
\hline Systolic blood pressure, $\mathrm{mmHg}$ & $147 \pm 19$ & $139 \pm 31$ & 0.37 \\
\hline Diastolic blood pressure, $\mathrm{mmHg}$ & $85 \pm 14$ & $81 \pm 23$ & 0.53 \\
\hline Heart rate, /min & $88 \pm 14$ & $85 \pm 18$ & 0.51 \\
\hline Body temperature $\geq 37^{\circ} \mathrm{C}, \%$ & 72.2 & 61.9 & 0.50 \\
\hline Smoking & & & 0.95 \\
\hline Current, \% & 8.3 & 5.6 & \\
\hline Former, \% & 25.0 & 27.8 & \\
\hline Never, \% & 66.7 & 66.7 & \\
\hline Diabetes mellitus, \% & 16.7 & 52.4 & 0.021 \\
\hline Myocardial infarction, \% & 0 & 0 & $>0.99$ \\
\hline Heart failure, $\%$ & 5.6 & 0 & 0.27 \\
\hline Stroke, \% & 5.6 & 9.5 & 0.64 \\
\hline $\begin{array}{l}\text { Chronic obstructive pulmonary } \\
\text { disease, \% }\end{array}$ & 0 & 4.8 & 0.35 \\
\hline Chronic kidney disease, $\%$ & 5.6 & 9.5 & 0.64 \\
\hline $\begin{array}{l}\text { Immunosuppressed } \\
\text { condition, \% }\end{array}$ & 0 & 0 & $>0.99$ \\
\hline \multicolumn{4}{|l|}{ Medications on admission } \\
\hline Direct renin inhibitor, \% & 0 & 0 & $>0.99$ \\
\hline Calcium channel blocker, \% & 50.0 & 61.9 & 0.45 \\
\hline$\beta$-blocker, $\%$ & 0 & 9.5 & 0.18 \\
\hline Antidiabetic drugs, $\%$ & 11.1 & 38.1 & 0.054 \\
\hline Statin, \% & 16.7 & 33.3 & 0.23 \\
\hline \multicolumn{4}{|l|}{ Laboratory data on admission } \\
\hline Leukocytes, $10^{9} / 1$ & $5.2(4.2-6.2)$ & $5.5(4.5-7.2)$ & 0.57 \\
\hline Neutrophils, $10^{9} / 1$ & $3.6(3.0-4.8)$ & $3.9(3.0-5.0)$ & $>0.99$ \\
\hline Platelets, $10^{9} / 1$ & $170(152-241)$ & $195(164-275)$ & 0.22 \\
\hline Hemoglobin, g/dl & $14.4(13.1-15.5)$ & $13.0(11.2-14.7)$ & 0.13 \\
\hline AST, IU/l & $49 \pm 30$ & $38 \pm 21$ & 0.19 \\
\hline ALT, IU/l & $45 \pm 36$ & $34 \pm 28$ & 0.29 \\
\hline$\gamma$-GTP, IU/l & $64 \pm 44$ & $55 \pm 40$ & 0.54 \\
\hline Total bilirubin, $\mathrm{mg} / \mathrm{dl}$ & $0.8 \pm 0.6$ & $0.6 \pm 0.3$ & 0.27 \\
\hline Total protein, g/dl & $6.7 \pm 0.5$ & $6.8 \pm 0.5$ & 0.51 \\
\hline Albumin, g/dl & $3.3 \pm 0.5$ & $3.5 \pm 0.6$ & 0.31 \\
\hline Glucose, $\mathrm{mg} / \mathrm{dl}$ & $130(107-143)$ & $120(108-230)$ & 0.68 \\
\hline Total cholesterol, mg/dl & $152 \pm 16$ & $150 \pm 32$ & 0.92 \\
\hline LDL-cholesterol, mg/dl & $91 \pm 12$ & $58 \pm 23$ & 0.016 \\
\hline HDL-cholesterol, mg/dl & $58 \pm 22$ & $42 \pm 13$ & 0.39 \\
\hline Trigrycerides, mg/dl & $101(72-125)$ & $119(82-239)$ & 0.44 \\
\hline Creatinine, mg/dl & $1.1 \pm 0.7$ & $1.0 \pm 0.8$ & 0.77 \\
\hline BUN, mg/dl & $21 \pm 16$ & $17 \pm 11$ & 0.33 \\
\hline $\mathrm{Na}, \mathrm{mEq} / \mathrm{l}$ & $137 \pm 4$ & $137 \pm 4$ & 0.65 \\
\hline Urine protein ( 23 patients) & & & 0.63 \\
\hline,$- \%$ & 20.0 & 7.7 & \\
\hline, $\pm \%$ & 20.0 & 30.8 & \\
\hline,$+ \%$ & 60.0 & 61.5 & \\
\hline $\mathrm{C}$-reactive protein, $\mathrm{mg} / \mathrm{dl}$ & $6.4(1.6-11.4)$ & $4.5(0.8-7.4)$ & 0.20 \\
\hline
\end{tabular}

Data are shown as mean \pm standard deviation, median (interquartile range), or percentage

$A C E-I$ angiotensin converting enzyme inhibitor, $A L T$ alanine aminotransferase, $A S T$ aspartate transaminase, $A R B$ angiotensin II receptor blocker, $B U N$ blood urea nitrogen, COVID-19 coronavirus disease-2019, $H D L$ high density lipoprotein, $L D L$ low density lipoprotein 
patient had pancreatic carcinoma in addition to suspected pneumonia and required oxygen therapy for low percutaneous oxygen saturation $\leq 90 \%$. In this case, the exact etiology of confusion could not be strictly determined. Twenty-two (14.6\%) patients were admitted to the ICU. In the results of univariate regression analyses, older age ( $\geq 65$ years) and diabetes mellitus were significantly associated with a higher risk of the primary composite outcome, and older age, diabetes mellitus, and hypertension were associated with the secondary composite outcome (Table 3). Older age, diabetes mellitus, hypertension, and a history of cerebrovascular or cardiovascular disease were associated with the "severe pneumonia" composite outcome, which included inhospital death related to pneumonia, extracorporeal membrane oxygenation, mechanical ventilation, and oxygen therapy (Table 3 ). In the multivariate logistic regression analysis, only older age ( $\geq 65$ years) remained an independent factor associated with the composite outcomes.

\section{Comparison of the primary and secondary composite outcomes and the "severe pneumonia" composite outcome between the hypertension group and the nonhypertension group in COVID-19 patients}

We then compared the primary and secondary composite outcomes and the "severe pneumonia" composite outcome between COVID-19 patients with hypertension and those without hypertension. In addition to "severe pneumonia", hypertension was associated with the secondary composite outcome and the presence of evidence of pneumonia by CT scan (Fig. 1 and Table 4). However, after adjustment for age, sex, and diabetes mellitus, hypertension was not associated with primary or secondary outcomes or the "severe pneumonia" composite outcome.

Table 3 Logistic regression analysis for the primary, secondary, and "severe pneumonia" composite outcomes

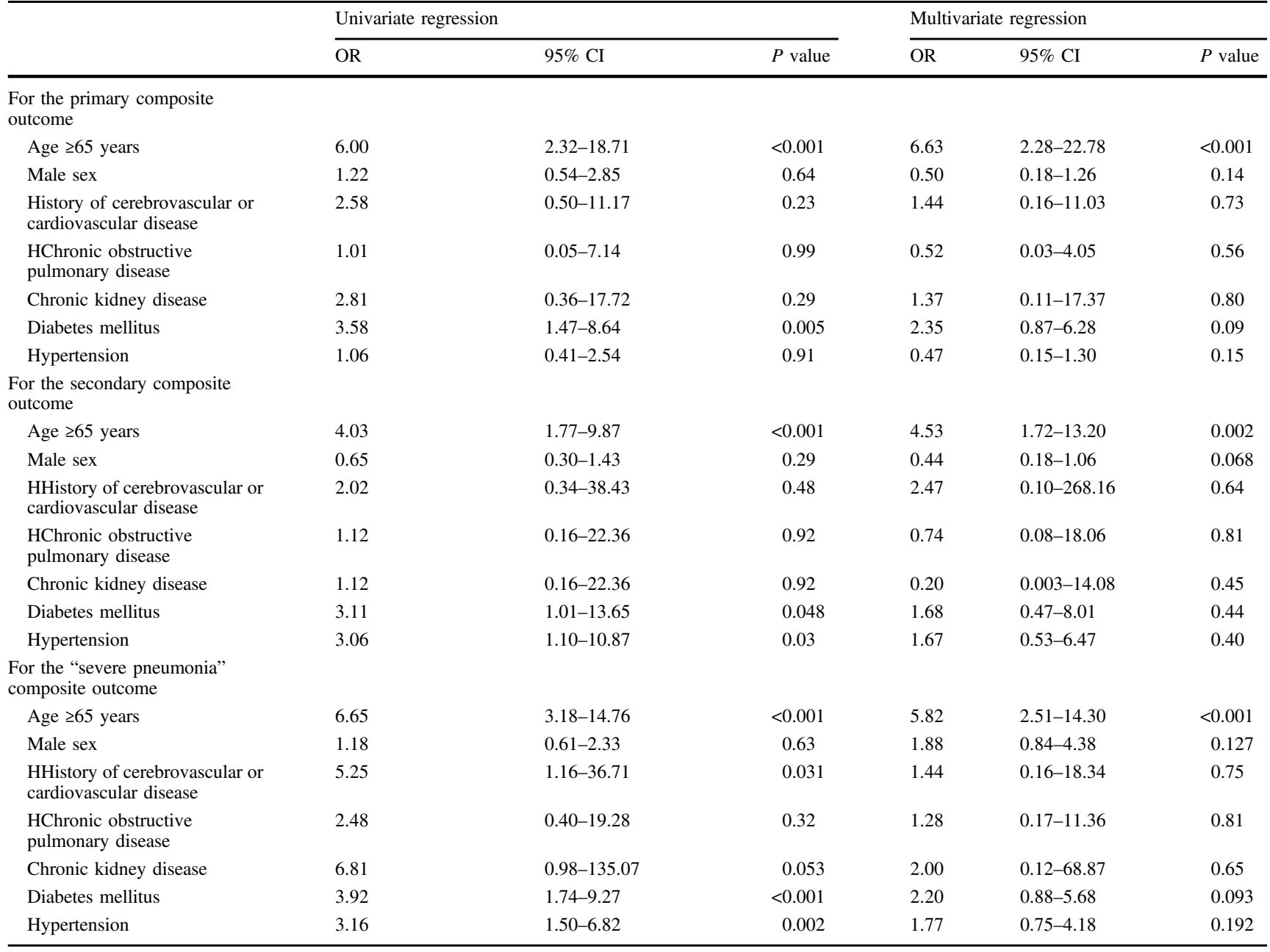

Composite of primary outcomes includes in-hospital death, ECMO, mechanical ventilation, and ICU admission. Severe pneumonia is defined as a composite of in-hospital death related to pneumonia, ECMO, mechanical ventilation, and oxygen therapy

CI confidence interval, $O R$ odds ratio 
(A)

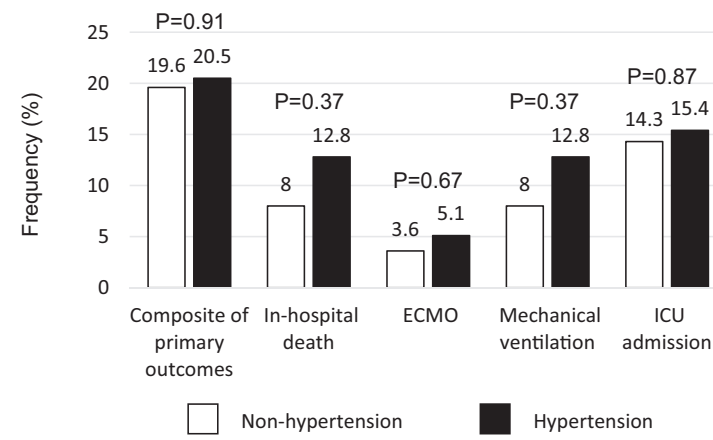

(B)

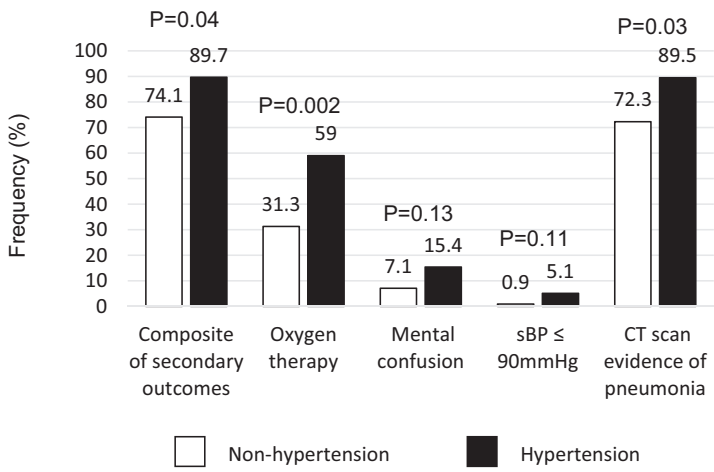

(C)

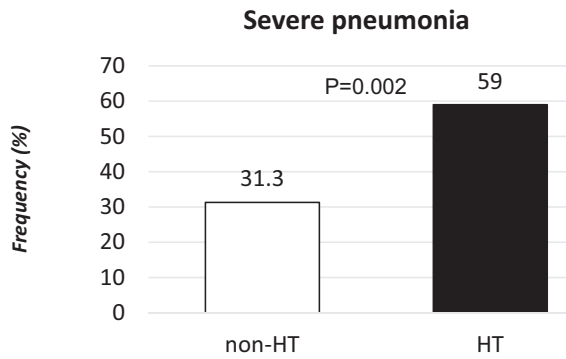

Fig. 1 Comparison of primary, secondary, and "severe pneumonia" composite outcomes between COVID-19 patients with hypertension and those without. Frequencies of primary (a), secondary (b), and "severe pneumonia" (c) composite outcomes. $P$ values were calculated with Fisher's exact test. The primary composite outcome included inhospital death, ECMO, mechanical ventilation, and ICU admission. The secondary composite outcome included oxygen therapy, mental confusion, systolic blood pressure $\leq 90 \mathrm{mmHg}$, and evidence of pneumonia by CT. The severe pneumonia composite outcome included in-hospital death related to pneumonia, ECMO mechanical ventilation, and oxygen therapy. COVID-19 coronavirus disease 2019, CT computed tomography, ECMO extracorporeal membrane oxygenation, ICU intensive care unit, sBP systolic blood pressure

\section{Primary and secondary composite outcomes and the "severe pneumonia" composite outcome according to preceding ACEI/ARB use in COVID-19 patients with hypertension}

Although the incidence of in-hospital death $(9.5 \%$ versus $16.7 \%)$, mechanical ventilation $(9.5 \%$ versus $16.7 \%)$, ICU admission (9.5\% versus $22.2 \%$ ), primary composite outcome (14.3\% versus $27.8 \%)$, and the "severe pneumonia" composite outcome $(52.4 \%$ versus $66.7 \%)$ were numerically lower in hypertension patients with ACEI/ARB use than in those without, there was no significant difference (Fig. 2). Five (27.8\%) patients in the non-ACEI/ARB group experienced new-onset confusion, compared to one $(4.8 \%)$ patient in the ACEI/ARB group (odds ratio of confusion onset in ACEI/ARB-using patients $0.13,95 \%$ CI $0.01-0.93, P=0.041$ ) (Fig. $2 b$ and Table 5). The association between ACEI/ARB use and a lower occurrence of mental confusion remained significant even after adjustment for age, sex, and diabetes mellitus (adjusted odds ratio 0.06, 95\% CI 0.002-0.69, $P=0.02$ ) (Table 5). The patient with confusion in the ACEI/ARB group was a centenarian. This patient suffered from multiple organ failure and shock and died several days after admission without any wish for invasive therapies, including mechanical ventilation. The frequency of the other secondary outcomes, including oxygen therapy, systolic blood pressure $\leq 90 \mathrm{mmHg}$, and evidence of pneumonia by CT scan, were not different between the two groups (Fig. 2b). The median length (in days) of hospital stay was not significantly different between the ACEI/ARB group and the nonACEI/ARB group (ACEI/ARB group 22 (15-26) days versus non-ACEI/ARB group 20 (17-28) days, $P=$ $0.84)$.

\section{Discussion}

The major findings of the present study were as follows: hypertension was associated with the "severe pneumonia" composite outcome that included in-hospital death related to pneumonia, extracorporeal membrane oxygenation, mechanical ventilation, and oxygen therapy. Evidence of pneumonia on CT scans was more prevalent in COVID-19 patients with hypertension than in those without hypertension. However, in the multivariate model with age, sex, and diabetes mellitus, hypertension was not associated with severe pneumonia, and older age was the only factor associated with worse outcomes. In COVID-19 patients with hypertension, ACEI/ARB use was associated with a lower occurrence of confusion. To the best of our knowledge, this is the first study in Japan to examine the clinical data of COVID-19 patients in the COVID-19 pandemic area.

\section{Beneficial effect of ACEIs/ARBs against COVID-19}

When SARS-CoV-2 enters cells, it is endocytosed together with its receptor, ACE2, resulting in the downregulation of ACE2 on the cell membrane [12]. The 
Table 4 Hypertension versus non-hypertension on outcomes

\begin{tabular}{|c|c|c|c|c|c|c|}
\hline & $\begin{array}{l}\text { Crude OR } \\
\text { HT vs non-HT }\end{array}$ & $95 \% \mathrm{CI}$ & $P$ & $\begin{array}{l}\text { Multivariate OR } \\
\text { HT vs non-HT }\end{array}$ & $95 \% \mathrm{CI}$ & $P$ \\
\hline \multicolumn{7}{|l|}{ Primary outcomes } \\
\hline Primary composite outcome & 1.06 & $0.41-2.54$ & 0.91 & 0.41 & $0.14-1.11$ & 0.08 \\
\hline In-hospital death & 1.68 & $0.49-5.23$ & 0.39 & 0.63 & $0.15-2.34$ & 0.49 \\
\hline ECMO & 1.46 & $0.20-7.80$ & 0.68 & 0.88 & $0.11-5.50$ & 0.89 \\
\hline Mechanical ventilation & 1.68 & $0.49-5.23$ & 0.39 & 1.08 & $0.28-3.76$ & 0.91 \\
\hline ICU admission & 1.09 & $0.37-2.90$ & 0.87 & 0.51 & $0.15-1.48$ & 0.22 \\
\hline \multicolumn{7}{|l|}{ Secondary outcomes } \\
\hline Secondary composite outcome & 3.06 & $1.10-10.87$ & 0.03 & 1.69 & $0.55-6.40$ & 0.38 \\
\hline Oxygen therapy & 3.16 & $1.50-6.82$ & 0.002 & 1.34 & $0.56-3.15$ & 0.51 \\
\hline Mental confusion & 2.36 & $0.73-7.29$ & 0.145 & 1.05 & $0.29-3.63$ & 0.94 \\
\hline Systolic blood pressure $\leq 90 \mathrm{mmHg}$ & 5.95 & $0.55-130.0$ & 0.136 & 2.04 & $0.54-7.91$ & 0.29 \\
\hline Pneumonia evidence by $\mathrm{CT}$ & 3.25 & $1.17-11.56$ & 0.022 & 1.29 & $0.39-5.63$ & 0.69 \\
\hline "Severe pneumonia" composite outcome & 3.16 & $1.50-6.82$ & 0.002 & 1.34 & $0.56-3.15$ & 0.51 \\
\hline
\end{tabular}

The primary composite outcome includes in-hospital death, ECMO, mechanical ventilation, and ICU admission. The secondary composite outcome includes oxygen therapy, mental confusion, systolic blood pressure $\leq 90 \mathrm{mmHg}$, and pneumonia evidence by CT. "Severe pneumonia" is defined as a composite of in-hospital death related to pneumonia, ECMO, mechanical ventilation, and oxygen therapy. ORs and P values were calculated with logistic regression analysis. Multivariate ORs were adjusted for age, sex, and diabetes mellitus

$C I$ confidence interval, $C T$ computed tomography, ECMO extracorporeal membrane oxygenation, $I C U$ intensive care unit, $H T$ hypertension, $O R$ odds ratio

reduction in ACE2 activity promotes the accumulation of angiotensin II and its binding to angiotensin receptor type 1 to cause the hyperactivation of the RAS [13], which elicits massive production of inflammatory cytokines, including tumor necrosis factor $\alpha(\mathrm{TNF} \alpha)$ and interleukin6 (IL-6) [14]. Thus, the downregulation of ACE2 and the hyperactivation of the RAS play critical roles in the deterioration of COVID-19, resulting in lung injury, the failure of other organs, and ARDS. ACEIs and $\mathrm{ARBs}$ are reportedly suggested to reduce inflammation by blocking the downregulation of ACE2 and the hyperactivation of the RAS [11]. Thus, RAS inhibition by ACEIs and ARBs may prevent the progression of acute lung injury in SARS-CoV-2 infection. Notably, in preclinical studies, the administration of recombinant ACE2 is protective against acute lung injury [15-17]. A number of clinical studies have reported an association between RAS inhibitors and the severity of COVID-19 [9, 18-20]. Some of them have reported a possible benefit of RAS inhibitors in COVID-19 patients; however, others have reported a neutral effect of RAS inhibitors on COVID-19. In any case, none of the studies showed that ACEIs/ARBs increased the likelihood of contracting COVID-19 or worsened the outcome of SARS-CoV-2 infections. The results of the current study were consistent with these previous studies. Recently, a small study of 42 patients with hypertension and COVID-19 was reported by Meng et al. [19]. Among patients taking ACEIs/ARBs $(n=17)$,
$23.5 \%$ of patients were categorized as having severe disease, whereas $48 \%$ of patients were categorized as having severe disease in the non-ACEI/ARB group. The level of IL-6 tended to be lower in the ACEI/ARB group than in the non-ACEI/ARB group. Furthermore, the peak viral load quantified by the PCR cycle threshold in the ACEI/ARB group was significantly lower than that in the non-ACEI/ARB group [19]. Notably, in a large study of 1128 adult patients with hypertension and COVID-19 by Zhang et al. [20], the incidence of 28-day mortality was less than half in patients ACEI/ARB users compared with ACEI/ARB nonusers; this association remained significant after matching and adjustment for confounding factors.

Although frequencies of in-hospital death, mechanical ventilation and the need for oxygen therapy tended to be lower in the ACEI/ARB group than in the non-ACEI/ARB group in the current study, we could not detect any significant associations between ACEI/ARB use and the primary outcomes. Several explanations may account for these negative findings. First, the number of patients included in our study was small. The number of patients with hypertension was 39; moreover, ACEIs/ARBs were prescribed in only 21 patients with hypertension. Second, ARBs were predominantly prescribed (rather than ACEIs) in this study population (ARBs: 18; ACEIs: 3 in patients with hypertension). The difference between ACEIs and ARBs in the association with COVID-19 is still unclear. 
(A)

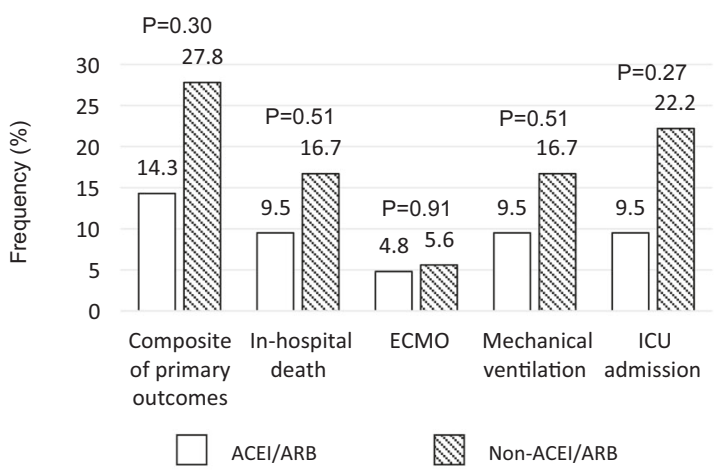

(B)

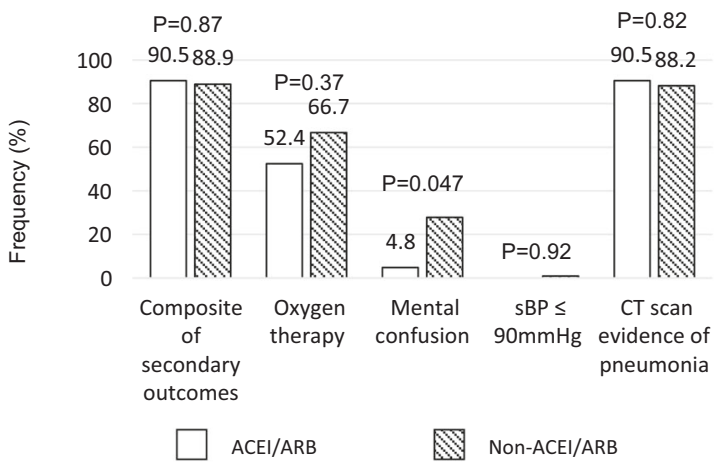

(C)

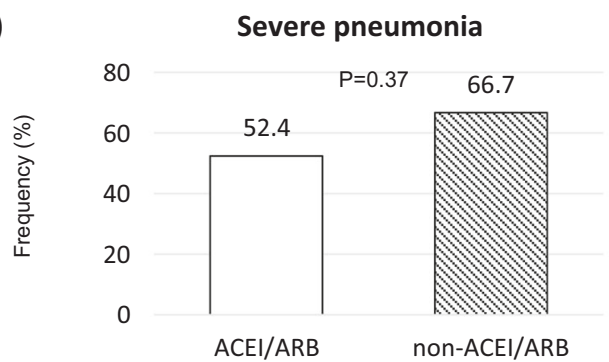

Fig. 2 Comparison of primary, secondary, and "severe pneumonia" composite outcomes between hypertensive COVID-19 patients with preceding ACEI/ARB use and those without. Frequencies of primary (a), secondary (b), and "severe pneumonia" (c) composite outcomes. $P$ values were calculated with Fisher's exact test. The primary composite outcome included in-hospital death, ECMO, mechanical ventilation, and ICU admission. The secondary composite outcome included oxygen therapy, mental confusion, systolic blood pressure $\leq 90 \mathrm{mmHg}$, and evidence of pneumonia by CT. The severe pneumonia composite outcome included in-hospital death related to pneumonia, ECMO, mechanical ventilation, and oxygen therapy. Frequencies of primary outcomes (a) and secondary outcomes (b). $P$ values were calculated with Fisher's exact test. ACEI angiotensin converting enzyme inhibitor, ARB angiotensin II type 1 receptor blocker, COVID-19 coronavirus disease 2019, CT computed tomography, ECMO extracorporeal membrane oxygenation, ICU intensive care unit, sBP systolic blood pressure

Due to the small number of patients, we could not analyze ACEIs and ARBs separately. Third, diabetes mellitus was found to be associated with severe pneumonia and worse prognosis (Table 3), and comorbid diabetes mellitus was more prevalent in the ACEI/ARB group than in the nonACEI/ARB group $(52.4 \%$ versus $16.7 \%, P=0.02)$ (Table 2).

\section{ACEIs/ARBs may prevent COVID-19-induced confusion}

Confusion in patients with COVID-19 is a manifestation of many factors. Potential factors include cerebral hypoxia, metabolic dysregulation, direct invasion of the central nervous system by SARS-CoV-2, and the failure of other organ systems, such as ARDS, heart failure, renal failure, and disseminated intravascular coagulation [21]. The neuroinflammatory reaction is suggested to be a key factor for acute brain dysfunction in critical illnesses [22]. Under activated systemic inflammation, blood-brain barrier permeability is increased, and the expression of tight junction proteins is altered, resulting in a disruption of the blood-brain barrier and the spread of inflammation into the central nervous system [22]. The protective effect of RAS inhibitors against inflammation [11,19] may be one possible mechanism for the relationship between ACEI/ ARB use and a lower occurrence of confusion in the current study.

\section{Limitations}

The results of the present study cannot be generalized to other populations with COVID-19. In this study, in-hospital mortality was $9.3 \%$, which is higher than the world statistics (6.2\% mortality as of May 30, 2020; https://coronavirus.jhu. edu/map.html). Because we enrolled only patients who were hospitalized, there is a selection bias. Moreover, the number of patients included in this study was small, and cytokine levels were not measured. Health-care providers were limited in contacting patients with COVID-19 to minimize their risk of infection. Therefore, we could not obtain some details of patients' information, including past medical history, family history, physical examination, etc. Since the current study is a retrospective observational study, the role of ACEIs/ARBs in COVID-19 needs to be further investigated.

\section{Conclusions}

Although the severity of COVID-19 was higher in patients with hypertension than in patients without hypertension in the univariate model, older age was the most important factor associated with worse prognosis in patients with COVID-19 in the multivariate models. Among COVID-19 patients with hypertension, ACEI/ARB use was associated with a lower occurrence of confusion during pneumonia. 
Table 5 ACEI/ARB versus non-ACEI/ARB on outcomes

\begin{tabular}{|c|c|c|c|c|c|c|}
\hline & $\begin{array}{l}\text { Crude OR } \\
\text { ACEI/ARB vs } \\
\text { non-ACEI/ARB }\end{array}$ & $95 \% \mathrm{CI}$ & $P$ & $\begin{array}{l}\text { Multivariate OR } \\
\text { ACEI/ARB vs } \\
\text { non-ACEI/ARB }\end{array}$ & $95 \% \mathrm{CI}$ & $P$ \\
\hline \multicolumn{7}{|l|}{ Primary outcomes } \\
\hline Primary composite outcome & 0.43 & $0.08-2.09$ & 0.30 & 0.37 & $0.05-2.29$ & 0.28 \\
\hline In-hospital death & 0.53 & $0.06-3.57$ & 0.51 & 0.36 & $0.03-3.53$ & 0.38 \\
\hline ECMO & 0.85 & $0.03-22.58$ & 0.91 & 0.81 & $0.02-33.85$ & 0.91 \\
\hline Mechanical ventilation & 0.53 & $0.06-3.57$ & 0.51 & 0.24 & $0.02-2.28$ & 0.22 \\
\hline ICU admission & 0.37 & $0.05-2.16$ & 0.27 & 0.46 & $0.03-4.47$ & 0.51 \\
\hline \multicolumn{7}{|l|}{ Secondary outcomes } \\
\hline Secondary composite outcome & 1.19 & $0.13-10.82$ & 0.87 & 0.86 & $0.07-9.78$ & 0.90 \\
\hline Oxygen therapy & 0.55 & $0.14-1.99$ & 0.36 & 0.47 & $0.10-1.99$ & 0.31 \\
\hline Mental confusion & 0.13 & $0.01-0.93$ & 0.041 & 0.06 & $0.002-0.69$ & 0.02 \\
\hline Systolic blood pressure $\leq 90 \mathrm{mmHg}$ & & Not assessed & & & Not assessed & \\
\hline Pneumonia evidence by CT & 1.27 & $0.14-11.59$ & 0.82 & 0.85 & $0.12-6.40$ & 0.87 \\
\hline "Severe pneumonia" composite outcome & 0.55 & $0.14-1.99$ & 0.36 & 0.47 & $0.10-1.99$ & 0.31 \\
\hline
\end{tabular}

The primary composite outcome includes in-hospital death, ECMO, mechanical ventilation, and ICU admission. The secondary composite outcome includes oxygen therapy, mental confusion, systolic blood pressure $\leq 90 \mathrm{mmHg}$, and pneumonia evidence by CT. "Severe pneumonia" is defined as a composite of in-hospital death related to pneumonia, ECMO, mechanical ventilation, and oxygen therapy. ORs and $P$ values were calculated with logistic regression analysis. Multivariate ORs were adjusted for age, sex, and diabetes mellitus

$A C E I$ angiotensin converting enzyme inhibitor, $A R B$ angiotensin II type 1 receptor blocker, $C I$ confidence interval, $C T$ computed tomography, $E C M O$ extracorporeal membrane oxygenation, $I C U$ intensive care unit, $O R$ odds ratio

Further studies are needed to elucidate the potential beneficial effects of ACEIs/ARBs on COVID-19.

Acknowledgements This work was supported by grants from the Japan Society for the Promotion of Science, Salt Science Research Foundation (20C4), the Japan Agency for Medical Research and Development (AMED), and Yokohama City University "KAMOME Project". The institutional review board of Yokohama City University approved this study (B200500052).

\section{Compliance with ethical standards}

Conflict of interest $\mathrm{K}$ Tamura has received lecture fees from DaiichiSankyo, Mochida, Kyowa Kirin, Boehringer Ingelheim Japan, Dainippon-Sumitomo, Takeda, and AstraZeneca and has received research grants from AstraZeneca, Ono Pharmaceutical, Boehringer Ingelheim Japan, Teijin Pharma, Mochida, Daiichi-Sankyo, Takeda, Kyowa Kirin, Dainippon-Sumitomo, Tsumura, and Bayer Japan outside the submitted work. The authors declare that they have no conflict of interest.

Publisher's note Springer Nature remains neutral with regard to jurisdictional claims in published maps and institutional affiliations.

\section{References}

1. Itoh H. A new normal for hypertension medicine with coronavirus disease-2019 (COVID-19): proposal from the president of the Japanese Society of Hypertension. Hypertens Res. 2020. https://doi.org/10.1038/s41440-020-0497-y) [Epub ahead of print].
2. Shibata $\mathrm{S}$, Arima $\mathrm{H}$, Asayama K, Hoshide S, Ichihara A, Ishimitsu $\mathrm{T}$, et al. Hypertension and related diseases in the era of COVID19; a report from the Japanese Society of Hypertension Task Force on COVID-19. Hypertens Res. 2020. https://doi.org/10.1038/ s41440-020-0515-0) [Epub ahead of print].

3. Lew TW, Kwek TK, Tai D, Earnest A, Loo S, Singh K, et al. Acute respiratory distress syndrome in critically ill patients with severe acute respiratory syndrome. JAMA. 2003;290:374-80.

4. Peiris JS, Chu CM, Cheng VC, Chan KS, Hung IF, Poon LL, et al. Clinical progression and viral load in a community outbreak of coronavirus-associated SARS pneumonia: a prospective study. Lancet. 2003;361:1767-72.

5. Nicholls JM, Poon LL, Lee KC, Ng WF, Lai ST, Leung CY, et al. Lung pathology of fatal severe acute respiratory syndrome. Lancet. 2003;361:1773-8

6. Ferrario CM, Jessup J, Chappell MC, Averill DB, Brosnihan KB, Tallant EA, et al. Effect of angiotensin-converting enzyme inhibition and angiotensin II receptor blockers on cardiac angiotensinconverting enzyme 2. Circulation. 2005;111:2605-10.

7. Furuhashi M, Moniwa N, Mita T, Fuseya T, Ishimura S, Ohno K, et al. Urinary angiotensin-converting enzyme 2 in hypertensive patients may be increased by olmesartan, an angiotensin II receptor blocker. Am J Hypertens. 2015;28:15-21.

8. Mehta N, Kalra A, Nowacki AS, Anjewierden S, Han Z, Bhat P, et al. Association of use of angiotensin-converting enzyme inhibitors and angiotensin II receptor blockers with testing positive for coronavirus disease 2019 (COVID-19). JAMA Cardiol. 2020; e201855. https://doi.org/10.1001/jamacardio.2020.1855 [Epub ahead of print].

9. Mancia G, Rea F, Ludergnani M, Apolone G, Corrao G. ReninAngiotensin-Aldosterone System Blockers and the Risk of Covid19. N Engl J Med. 2020;382:2431-40.

10. Kai H, Kai M. Interactions of coronaviruses with ACE2, angiotensin II, and RAS inhibitors-lessons from available evidence and insights into COVID-19. Hypertens Res. 2020;43:648-54. 
11. de Wit E, van Doremalen N, Falzarano D, Munster VJ. SARS and MERS: recent insights into emerging coronaviruses. Nat Rev Microbiol. 2016;14:523-34.

12. Kuba K, Imai Y, Rao S, Gao H, Guo F, Guan B, et al. A crucial role of angiotensin converting enzyme 2 (ACE2) in SARS coronavirus-induced lung injury. Nat Med. 2005;11:875-9.

13. Liu Y, Yang Y, Zhang C, Huang F, Wang F, Yuan J, et al. Clinical and biochemical indexes from 2019-nCoV infected patients linked to viral loads and lung injury. Sci China Life Sci. 2020;63:364-74.

14. Hirano T, Murakami M. COVID-19: a new virus, but a familiar receptor and cytokine release syndrome. Immunity. 2020;52:731-3.

15. Imai Y, Kuba K, Rao S, Huan Y, Guo F, Guan B, et al. Angiotensin-converting enzyme 2 protects from severe acute lung failure. Nature. 2005;436:112-6.

16. Zou Z, Yan Y, Shu Y, Gao R, Sun Y, Li X, et al. Angiotensinconverting enzyme 2 protects from lethal avian influenza A H5N1 infections. Nat Commun. 2014;5:3594.

17. Gu H, Xie Z, Li T, Zhang S, Lai C, Zhu P, et al. Angiotensinconverting enzyme 2 inhibits lung injury induced by respiratory syncytial virus. Sci Rep. 2016;6:19840.
18. Li J, Wang X, Chen J, Zhang H, Deng A. Association of reninangiotensin system inhibitors with severity or risk of death in patients with hypertension hospitalized for coronavirus disease 2019 (COVID-19) infection in Wuhan, China. JAMA Cardiol. 2020;5:1-6. https://doi.org/10.1001/jamacardio.2020.1624. [Epub ahead of print].

19. Meng J, Xiao G, Zhang J, He X, Ou M, Bi J, et al. Reninangiotensin system inhibitors improve the clinical outcomes of COVID-19 patients with hypertension. Emerg Microbes Infect. 2020;9:757-60.

20. Zhang P, Zhu L, Cai J, Lei F, Qin JJ, Xie J, et al. Association of inpatient use of angiotensin-converting enzyme inhibitors and angiotensin II receptor blockers with mortality among patients with hypertension hospitalized with COVID-19. Circ Res. 2020;126:1671-81.

21. Kotfis K, Williams Roberson S, Wilson JE, Dabrowski W, Pun BT, Ely EW. COVID-19: ICU delirium management during SARS-CoV-2 pandemic. Crit Care. 2020;24:176.

22. Cerejeira J, Firmino H, Vaz-Serra A, Mukaetova-Ladinska EB. The neuroinflammatory hypothesis of delirium. Acta Neuropathol. 2010;119:737-54. 